\title{
Action Research Methodology as a Managerial Tool: Discussion and Implications
}

\author{
Bayan Yousef Farhan \\ College of Business \\ Al Ain University of Science and Technology, UAE \\ *bayan.farhan@aau.ac.ae
}

\begin{abstract}
The purpose of this paper is to contribute to a better understanding of action research methodology as a managerial tool. A practical example was employed to explain the dynamic process of action research and its role in understanding a managerial problem: observe, reflect, plan, \& act. This paper argues that the implementation of this tool in organizations can be considered as a foundation for managerial problem solving. Employing action research can facilitate the crafting of appropriate strategies and lead to highly desirable results, and thus three points should be recognized: (1) the intention in a given situation is to get a deep understanding and to construct a social reality based on participants' perceptions; (2) involving managers to help in understanding what might be done to improve the situation and what action should be implemented to overcome the problem; (3) implementing the recommended solutions (action), as well as repeating and evaluating the process is to be considered the cornerstone to improve an undesired situation.
\end{abstract}

Keywords: Action Research; Action Plans; Managerial Tool; Managerial Problem.

\section{Introduction}

Action research is an applied research methodology that can be used as a tool in the practice of management and "for bridging theory and practice in organization and management studies" (Bartels, 2012, p. 435). It has always been used in situations where a deeper understanding of a given problem is needed, and where the input of participants is used to develop this deeper understanding. Furthermore, action research has also been used as a research methodology by researchers in applied research studies to address social problems and to build knowledge. Thus, the question of how do we know what we know; which was highlighted by Crotty (1998) can be the prerequisite for choosing an appropriate methodology for a given scenario or problem. In economics research, researchers' subjectivity is normally unwelcomed and the doors are widely open for mathematical and statistical analysis. However, due to the fact that academic disciplines "are not created equal", problems are different as well, other ways of knowing can be utilized to reach a deep understanding of some phenomena.

The purpose of this paper is to contribute to better understanding of action research methodology as a managerial tool. This paper argues that the implementation of action research in organizations 
can be considered as a foundation for managerial problem solving. The significance of using action research as a managerial tool is to provide a rich understanding of a given problem and to potentially implement the right actions (strategies) to improve the situation. In using this approach, understanding the perceptions of stakeholders who are linked to the problem is critical in the improvement process (Hinchey, 2008). What can be unique in the use of action research is utilizing participants' experiences and knowledge that could lead to a rich understanding in developing action plans needed to improve the situation. Another aim of this paper is to provide a practical explanation of action research methodology as a managerial tool to understand and overcome managerial problems in academic institutions. This explanation requires, first, explaining the meaning and the models of action research; and then, providing a practical example that explains how action research can be practiced to understand and improve undesired situations.

\section{Action Research as a Managerial Tool}

The changing nature of the social environment has affected the way researchers construct meaning and knowledge to enhance development and growth. According to McNiff and Whitehead (2001), it can be inappropriate to rely on objective-based truth in complex and changing societies. They also added that this has encouraged researchers to adopt action research as a methodology to construct social realities. Constructing truth which is based on people's experiences and thoughts, according to Hinchey (2008), was encouraged to get deep understanding for the purpose of learning and development. Hinchey's argument was supported by McNiff and Whitehead, who added that reflecting people's contradictions and their experiences into practice can lead to rich understanding. Also, action research can be seen as an excellent research methodology due to its rich analysis and explanation of real-life problems (Avison, 1999). One can assume that action research can be an appropriate managerial tool for understanding, improving, and overcoming problems in organizations. Thus, "the key idea is that action research uses a scientific approach to study the resolution of important social or organizational issues together with those who experience these issues directly" (Coghlan, Shani, Roth, \& Sloyan, 2014, p. 993).

In addition, action research methodology can help in developing new theories of participants' practice by critiquing some social phenomena, and by searching for solutions (Altrichter, Posch, $\&$ Somekh, 1993). Action research has linked theories and practices and facilitated their ability to work together, and according to Carson (1990), "the turn toward interpretation is now an effort to re-ground our understandings in practice” (p. 172). Also, action research as a tool for improvement and change has become a way of researching and constructing theories of practice (McNiff \& Whitehead, 2001). McNiff and Whitehead have also suggested that theories of practice that are already located in participants' knowledge and thoughts can be created by using the process of self- evaluation, and that may lead to personal and social benefits. However, Avison (1999) highlighted the important issue of people having different perceptions, thoughts, and attitudes; that may change over time, which makes action research an appropriate tool to address difficulties.

Action research has been extensively explained in literature, but this paper highlights action research as a managerial tool that can go beyond its methodological use. The paper proposes 
action research by making a link between three dimensions: an explanation of action research; an application of action research through providing a theoretical example; and an interpretation method for implementing the potential improvement plan. While many studies have focused on the theoretical side of action research methodology, the focus of this paper is on the practical side of it. A hypothetical example is proposed to help in clarifying the practical meaning of action research and to show how to implement action research cycles and its four stages as an improvement process, which might help those who would like to adopt this type of research methodology.

\section{The Meaning of Action Research}

There are two explanations of action research which were provided by Costello (2011): first, "action research is an enquiry which is carried out in order to understand, to evaluate and then to change, in order to improve some ... practice"; second, "Action research is a flexible spiral process which allows action (change, improvement) and research (understanding and knowledge) to be achieved at the same time" (p. 16). Indeed, action research as a practical tool will be used to construct knowledge that is based on evidence generated from the collected data (Hinchey, 2008). Also, analyzing the data and choosing a proper action will help in changing or improving the situation under study.

From another point of view, action research "refer[s] to research that involves multiple stakeholders and intends to change ... society at large" (Hinchey, 2008, p. 32). Interestingly, action research does not have a standard model that should be followed (Hinchey, 2008). Whereas Creswell (2008) defined action research as an applied design which tries to understand some problems in order to develop solutions for these problems. Also, action research can be defined as a collaborative work in which sharing information and experience can enhance quality (Hinchey, 2008). Indeed, the collaboration and cooperation between the outside management consultants and the inside practitioners (subordinates) is important in increasing the quality of the improvement processes. The rationale behind this cooperation is that insiders may have deep understanding of the problems and conditions, and outsiders (managers) can help through their professional experience.

Using action research to address a problem might be significant due to its processes of "reflection, planning, acting, observing, reflecting, and re-planning" (Carson, 1990, p.168). These practical processes can allow action research to fit properly in both academic and business environments. Action research and its continuous processes can allow for the participating groups (subordinates) to work and share their experiences and thoughts, and allow the silent voices of subordinates to be heard (Hinchey, 2008). Action research as a managerial tool allows insiders themselves to participate in all improvement processes in order to find the solutions for their own problems. Indeed, "we do need to consider the other people we work with truly as others and not merely as instruments on the way to producing preformed conclusions about what is good for them" (Carson, 1990, p. 172). Further, action research is useful in allowing marginalized people (workers) to participate in order to improve their situation (Hinchey, 2008).

Because of its nature, action research can produce a rich analysis of the problem by collecting 
data from those who are living with the problem, having a deep understanding of the situation, and by allowing them to construct and implement a plan that fits with their needs. Arguably, it is important to listen to those who have a weak voice in order to understand and explain an existing condition, and, indeed, to make a significant improvement for their daily life. The adoption of action research allows for understanding a situation and underlining a proper action (strategy) that can be implemented to solve or improve the problem.

\section{Action Research Models: Practical and Emancipatory}

The importance of action research can be seen through its goal of improving and changing a specific condition for one particular group, unit, or organizational department. According to Carson (1990), action research can provide deep analysis and understanding of a problem in order to change and reform undesired conditions. Mejía-Villa and Alfaro-Tanco (2017) argued that action research "could be considered as an open innovation practice" (p. 192). Whereas Hadfield (2012) has criticized the realities that are obtained from action research, and suggested that practitioners' ontological views can affect their self-reflections and their interpretations which in turns affect the suggested solutions and action plans. Thus, management should not ignore the importance of encouraging those who have a silent voice, as well as those who are unwilling to change the traditional way of doing things to be active practitioners.

Practical action research. The importance of practical action research can be seen through the process of sharing with insider stakeholders the efforts to identify a specific internal or local problem and to explore with them the strategies to make the desired change (Hinchey, 2008). For example, insiders at academic institutions who have a full understanding of teaching and learning problems can give good explanation of their local educational problems. At the same time, they can develop a plan for action in order to bring change and improvement. This approach can encourage the collaboration between practitioners who have a different ontological stance, and can also create superior ideas, strategies, plans, and actions.

Emancipatory action research. The importance of emancipatory action research is shown by its speciality as a research for justice (Hinchey, 2008). To reach social justice, according to Creswell (2008), the democratic practice was encouraged by empowering participants and treating them as equal. Moreover, emancipatory action research can be used to change and improve the quality of individuals' lives by making room for community stakeholders to participate in action research (Creswell, 2008; Hinchey, 2008). Indeed, the growing idea of enabling insider stakeholders to interact with outsiders in a community can create a significant improvement for practitioners and for the whole community. The positive effect of emancipatory action research in understanding and analyzing the elements that caused the problem have made it appropriate for various work environments. At the same time, and according to Creswell (2008), the importance of involving all stakeholders can encourage the democratic practice and reduce the bureaucracy behaviour which might enhance the improvement and reform policy. 


\section{The Practical Example: Action Research as a Managerial Tool in Academic Institutions}

A practical example has been used to explore the procedures of action research in improving an undesired situation. The practical example, 'the role of financial aid in degree completion for female visible minority students at Maple Leaf University (MLU)', involves the related stakeholders (e.g., students, administrators, donors, and outsiders' consultants). The declining graduation rate among female visible minority students has led to many questions and has ignited many debates at Maple Leaf University (pseudonyms). Administrators at the university are interested in understanding the reasons behind this situation, how can they address it? And what might be done to improve the academic prospect of these students? Administrators at MLU suspect that students' financial difficulties might be one major cause of this problem. Therefore, students' affordability and accessibility at MLU became the main argument, and applied research was recommended to improve the undesired situation.

In this example, action research as a tool was employed to answer the question of what can be done to enhance degree completion and what actions (managerial strategies) should be implemented to avoid the problem. At the same time, diversity of practitioners can help in planning and implementing a proper action that might improve the situation under study.

\section{Action Research and Participants}

In Action research, solving a problem requires getting deep understanding by collaborating and cooperating among internal and external participants. The collaboration between both participants and practitioners can produce rich information based on participants' perceptions and interactions. Mejía-Villa and Alfaro-Tanco (2017) categorized practitioners into two types: classic practitioners who focus on analyzing organizational problems; and practitioners who act as internals and have active role in both analyzing problems and finding solutions. They all can work together and share their skills and knowledge in order to create a plan of action that may improve the undesired situation or solve a potential problem. Protecting participants' privacy rights and their personal information by using a secured place for meetings and discussions can provide a trusted environment for all participants.

To get reliable information and deep understanding, data will be collected from key stakeholders of the problem who are directly affected by it (Hinchey, 2008). Listening to those who are already affected by the problem could also provide rich information and enhance the reliability of the suggested actions. Focus groups can be used as a method of data collection. This method is defined by Creswell (2008) as "the process of collecting data through interviews with a group of people, typically four to six" (p. 226). Also, the purpose of using focus groups is to bring people together to explore their perceptions and opinions regarding the problem under study (Hinchey, 2008). The other purpose of using focus groups is to obtain a range of opinions and ideas to understand the diversity of participants' perspectives, and to seek participants' suggestions of alternative actions to be implemented (Bloomberg \& Volpe, 2008).

Discussing general points can be used as a suitable way to get additional information from participants (Hinchey, 2008). It is understood that using open discussion can be useful in 
collecting rich information and reaching deep understanding of the phenomenon. Also, it allows the group of participants to speak freely about any related issues. Furthermore, recording the collected data on audio and videotapes could be used to enhance the credibility, to avoid missing information, and to capture the participants' experiences through their own words (Creswell, 2008). At the same time, strong facilitation skills are required and might be helpful in managing the conversations (Creswell, 2008). The academic institution (MLU) appoints practicing managers to handle the project, and their role as facilitators allows all participants to talk freely by giving them enough time to participate, and also to prevent any one individual from dominating the conversation.

\section{Contradictions in Action Research}

In action research, participants' observations, experiences, and believes are playing an important role in constructing the plan and the action (Hinchey, 2008). At the same time, one finds it hard to ignore how participation managers' ontological stances may affect their interpretations and self-reflection. Therefore, ontological diversity among managers and participants, according to Hadfield (2012), may create such a conflict. This ontological contradiction can create an opportunity to challenge and critique own and other practitioners' reflections, and that may allow for reinterpretation. Arguably, managers' ontological contradictions may support the purpose of action research which is 'rich understanding'. At the same time, a rich understanding of the problem can help in making the right interpretations and in proposing acceptable plans and actions.

\section{The Dynamic Process of Action Research}

The process of action research was explained by Hinchey (2008) and includes: 1) identifying the problem; 2) collecting and analyzing data from subordinates; 3) implementing the action (strategy); 4) evaluating the action by re-collecting and analyzing data and repeating the action research process. This continuous improvement in action research can improve and change the conditions under study (Hinchey, 2008). This cyclical process is important for improvement and it represents a positive compound effect due to its continuous cycle. Moreover, this movement effect was confirmed by Carson (1990) who stated that action research is a proper tool due to its process of jointly working of "reflection, planning, acting, observing, reflecting, and replanning" (p.168).

However, action research has flexible processes that can be used to explain and solve the MLU expected problem. Therefore, the one cycle of action research (the four processes) can be summarized by the following:

1. Observe: observing the problem, describing it (identifying the situation that needs to be changed or improved).

2. Reflect: collecting the information (data) from participants and analyzing it. All participants' discussions and responses might be recorded in both video and audiotapes.

3. Plan: planning to act in order to find the proper action that needs to be implemented to improve the situation.

4. Act: implementing and reviewing the change. 
In general, there is a need for more than one cycle to improve the undesired situation by repeating the four processes of observing the change, re-reflecting, re-planning, and re-acting. Employing several cycles of action research will allow researchers and practicing managers to test, retest the data and to evaluate the reliability of the suggested and implemented solutions. On the other hand, and according to Costello (2011), action research process has eight stages to improve the situation under study. Stage 1 and 2 can identify and describe the problem. In stage 3, a manager can collect and report participants' responses to specific related discussion points (e.g. discussing the reasons behind the declining graduation rate among female visible minority students; discussing the role of financial aid in enhancing degree completion). In stage 4, a manager can review, then analyze the data and can write a brief summary of the findings. The manager's interpretations will be discussed with all participants in order to get their feedback and find a proper action. The discussion point (e.g., discussing all other options that might enhance graduation rates) can be explained by stage 5 . In stage 5, participants can suggest and introduce a proper action of change. A manager will monitor the change in stage 6 , analyze the data after implementation in stage 7, and review the change and propose the next step in stage 8 (Costello, 2011, p. 21).

\section{Action Research Cycles: MLU as a Hypothetical Example}

\section{The First Cycle (Baseline data before any intervention):}

1. Planning: explore the problem of why the graduation rate is low among female visible minority students at MLU. Because improving and changing this problem requires getting deep understanding, a manager needs to start by discussing the problem with those who are concerned about the situation and those who are interested in sharing their experiences and perceptions.

2. Acting: MLU has offered $\$ 100$ gift card for female visible minority students who agree to participate in focus group meetings. Donors and consultants have been contacted by academic vice-principal office at MLU, and they have agreed to participate.

3. Observing: bringing people together (all participants) in order to collect the baseline data (information about the status quo) by discussing three general points (Discussing the reasons behind declining graduation rate among female visible minority students; discussing the role of financial aid in enhancing degree completion; discussing the other options that might be considered to enhance graduation rate) with each cohort group, and exploring participants' perceptions and feelings about the problem.

4. Reflecting: analyzing the collected information (data analysis) by using recorded data (video-audiotapes) and a manager's observations and own field notes.

\section{The Second Cycle (Collecting Data after the First Intervention):}

1. Planning: Discussing a manager's interpretation and listening to participants' points of view and their feedback. It is also important at this stage to discuss the proper plan of action that might be implemented to improve the situation and one expected plan of action could be a textbooks allowance of $\$ 500.00$ for each focus group participating student.

2. Acting: creating the first change by implementing the textbooks allowance that will be funded by the donors. 
3. Observing: monitoring the change after the implementation and collecting data about the first change through discussing and listening to participants' perceptions. After the implementation, it is important to collect new information (data) by discussing the three general points that were mentioned above.

4. Reflecting: analyzing the collected data and creating the potential interpretation.

\section{The Third Cycle:}

1. Planning: discussing researcher's interpretation and getting feedback from participants. At this stage, it is possible to discuss a new plan of action if necessary.

2. Acting: introducing and implementing a new action plan that might improve the situation or solve the problem. It is possible to implement a new action plan of daycare allowance for those who have children under 7 years old. Introducing such social plan of action might help in improving the situation.

3. Observing: monitoring the change by collecting new data from participants.

4. Reflecting: analyzing the collected data and discussing the researcher's interpretation with research participants and also getting a peer feedback. At this stage, drawing the conclusion from the analyzed data and sharing the results with MLU administration office could be the final step in this problem-solving process through the use of action research.

\section{How to Organize the Collected Data at MLU}

Data analysis will start after each round of data collection. Organizing the raw data is essential before analyzing it, so the manager can follow two steps to label the data and to transform it into transcribed forms. The MLU managers should accurately transcribe the audio and videotapes of data into a written form as the first step in the analysis process. At the same time, managers need to check with participants the preciseness of the transcribed data, and get their feedback. In addition, the managers should start analyzing these transcribed (written) data by reviewing it and writing some notes and summaries. According to Hinchey (2008), reviewing these summaries by creating such index can help in comparing and organizing the data. Moreover, a report of research findings will be written directly when data analysis is completed. Coding and categorizing all participants' responses should also be employed to make managers' interpretations more reliable. Indeed, categorizing and sorting the collected data can be useful in managing and interpreting the collected information. Coding and categorizing of the first cycle can be seen in Appendix A. The second and third cycles will have own codes and categories, but will be similar to those in the first cycle (please see appendix A for more details about coding and categorizing).

\section{Limitations and Conclusion}

The purpose of employing this methodology is to contribute to a better understanding of a given problem. The implementation of action research in public or private organizations can support their development and change. "Action research generated considerable knowledge and understanding of the process of managing change" (Somekh, 2005, p. 125). This type of practical methodology helps both leaders and subordinates as change agents to improve their organizations. Adesi, Owusu-Manu, and Badu (2015) argued that action research methodology results could also be applied by organizations to improve their services. Proposing training on 
how to use action research is essential to understand the process of development, and can help in explaining the philosophy of action research. The philosophy is based on the collaboration and participation among organization's stakeholders to identify the need for change and how it can be implemented.

For future research opportunities, this paper recommends that action research could be implemented successfully if both business organizations, as community partners, and academic institutions work together. Collaboration among them serves the purpose of improving strategies, and understanding the needed skills that potential graduates should have. Allowing people to engage regardless of their positions, power, or perceptions can also help in improving academic programs to match market needs. Also, the paper suggests that public and private organizations need to use action research extensively as a continuing process of change and as a tool for knowledge development.

On the other hand, the subjectivity of interpretations can be seen as the first limitation in the use of action research. To avoid this limitation, managers could employ the following: 1) using audio-videotapes to correctly transcribe the recorded data. Using audio-videotapes will allow managers to watch and listen carefully to participants' perceptions. This type of recording can reduce the subjectivity of interpretation when this recorded data is transcribed into a written form; 2) Using field notes to document unusual events which cannot be captured by audio-videotapes during the discussion. Using field notes will allow managers to monitor participants' selfreflections and their subjectivity; 3) using general discussion points to facilitate the discussion and to reduce any possibilities that may influence participants' reflections. 


\section{References}

- Adesi, M., Owusu-Manu, D., \& Badu, E. (2015). Rethinking methodology in project management consulting context. International Journal of Construction Project Management, 7(2), 79-100.

- Altrichter, H., Posch, P., \& Somekh, B. (1993). Teachers investigate their work: An introduction to the methods of action research. Florence, KY, USA: Routledge. http://site. ebrary.com/lib/ucalgary/Doc?id=10095868\&ppg=17

- Avison, D. E. (1999). Action research. Magazine communication of the ACM. 42(1), 9497. Doi: $10.1145 / 291469.291479$.

- Bartels, K. P. R. (2012). The actionable researcher: Cultivating a process-oriented methodology for studying administrative practice. Administrative Theory \& Praxis, 34(3), 433-455.

- Bloomberg, L. \& Volpe, M. (2008). Completing your qualitative dissertation: A roadmap from beginning to end. (2nd ed). Los Angeles and London: Sage.

- Carson, T. (1990). What kind of knowing is critical action research? Theory into Practice, 29(3), 167-193.

- Coghlan, D., (Rami) Shani, A. B., Roth, J., \& Sloyan, R.,M. (2014). Executive development through insider action research: Voices of insider action researchers. The Journal of Management Development, 33(10), 991-1003.

- Costello, P. J. M. (2011). Effective action research: Developing reflective thinking and practice (2nd Edition). London, GBR: Continuum International Publishing. This book is available online at: http://education.costello.continuumbooks.com.

- Creswell, J. W. (2008). Educational research: Planning, conducting, and evaluating. Quantitative and qualitative research. Person Education, Inc., Upper Saddle River, New Jersey 07458.

- Crotty, M. (1998). The foundations of social research: Meaning and perspective in the research process. London, CA: Sage.

- Hadfield, M. (2012). Becoming critical again: Reconnecting critical social theory with the practice of action research. Educational Action Research, 20(4), 571-585.

- Hinchey, P. (2008). Action research primer. New York: Peter Lang

- McNiff, J. \& Whitehead, J. (2001). Action research: Principles and practice. (2nd Edition). London,GBR:FalmerPress.http://site.ebrary.com/lib/ucalgary/Doc?id=10096251\&ppg=23

- Mejía-Villa, A., \& Alfaro-Tanco, J. (2017). Action research projects: One step ahead in the researcher-practitioner relationships. Working Papers on Operations Management, 8, 191203. doi:http://dx.doi.org/10.4995/wpom.v8i0.7660

- Somekh, B. (2005). Action research: A methodology for change and development. Open University Press McGraw-Hill Education, England. Retrieved from https://ebookcentral. proquest.com. 


\section{Appendix A}

Coding and categorizing all participants' responses can be employed to make managers' interpretations more reliable. Colours, numbers, and symbols can be used to code the data (e.g. 20 Female Visible Minority Students (F1, F2, .., F20); 5 Donors (D1, D2, ..., D5); 5 Administrators (A1, A2, .., A5); 5 Consultants (CO1, CO2, .., CO5); Focus groups (FG); 3 Cycles of action research $(\mathrm{C} 1, \mathrm{C} 2, \mathrm{C} 3))$.

\begin{tabular}{|l|l|}
\hline 1- First Female Visible Minority Student. Focus Groups. Cycle \#1 & (F1FGC1) \\
\hline 1- First Donor. Focus Groups. Cycle \# 1 & (D1FGC1) \\
\hline 1- First Administrator. Focus Groups. Cycle \# 1 & (A1FGC1) \\
\hline 1- First Consultant. Focus Groups. Cycle \# 1 & (CO1FGC1) \\
\hline
\end{tabular}

Data collection focused on these three discussion points:

1. Discussing the reasons behind declining graduation rate among female visible minority students;

2. Discussing the role of financial aid in enhancing degree completion;

3. Discussing the other options that might be considered to enhance graduation rate) with each cohort group, and exploring participants' perceptions and feelings about the problem.

The collected data will be categorized by identifying each category before sorting it (Hinchey, 2008). These categories, for example, can be identified as:

a) Unambiguous meaning (e. g., express a point clearly, express an opinion and preferences clearly);

b) Attainable and not attainable plan (e. g, give appropriate plans and strategies of intervention to enhance the situation;

c) Participants' emotions and feelings about their suggested actions (e. g, give a reason, give many reasons, give own experience to support his/her argument).

A report of research findings will be written directly when data analysis is completed. Coding and categorizing of the first cycle can be seen in the following tables. The second and third cycles will have own codes and categories, but will be similar to those in the first cycle. 
Table 1.a. The first cycle: Comparing and Organizing the Data

\begin{tabular}{|c|c|c|c|c|}
\hline \multirow[b]{3}{*}{ Research Participants } & \multicolumn{4}{|c|}{ First Discussion Point } \\
\hline & \multicolumn{4}{|c|}{$\begin{array}{l}\text { Discussing the reasons behind declining graduation } \\
\text { rate among female visible minority students }\end{array}$} \\
\hline & $\begin{array}{l}\text { Give a } \\
\text { reason }\end{array}$ & $\begin{array}{l}\text { Give } \\
\text { many } \\
\text { reasons }\end{array}$ & $\begin{array}{c}\text { Give own } \\
\text { experience to } \\
\text { support his/her } \\
\text { argument }\end{array}$ & $\begin{array}{l}\text { Research- } \\
\text { er's Field } \\
\text { Notes }\end{array}$ \\
\hline \multicolumn{5}{|l|}{5 Administrators (A) } \\
\hline \multicolumn{5}{|l|}{$\begin{array}{l}\text { Administrator number one. Focus } \\
\text { groups. Cycle \# } 1 \text { (A1FGC1) }\end{array}$} \\
\hline \multicolumn{5}{|l|}{$\mathrm{A} 2 \mathrm{FGC} 1$} \\
\hline \multicolumn{5}{|l|}{ A3FGC1 } \\
\hline \multicolumn{5}{|l|}{ A4FGC1 } \\
\hline \multicolumn{5}{|l|}{ A5FGC1 } \\
\hline \multicolumn{5}{|l|}{$\begin{array}{l}20 \text { Female visible minority students } \\
\text { (F), focus groups participants (FG) }\end{array}$} \\
\hline \multicolumn{5}{|l|}{$\begin{array}{c}\text { Female visible minority student } \\
\text { number one, focus group, Cycle one } \\
\text { (F1FGC1) }\end{array}$} \\
\hline \multicolumn{5}{|l|}{ F2FGC1 } \\
\hline \multicolumn{5}{|l|}{ F3FGC1 } \\
\hline \multicolumn{5}{|l|}{$\ldots$} \\
\hline \multicolumn{5}{|l|}{ F20FGC1 } \\
\hline \multicolumn{5}{|l|}{5 Donors (D) } \\
\hline \multicolumn{5}{|l|}{$\begin{array}{c}\text { Donor number one. Focus groups. } \\
\text { Cycle \# } 1 \text { (D1FGC1) }\end{array}$} \\
\hline \multicolumn{5}{|l|}{ D2FGC1 } \\
\hline \multicolumn{5}{|l|}{ D3FGC1 } \\
\hline \multicolumn{5}{|l|}{ D4FGC1 } \\
\hline \multicolumn{5}{|l|}{ D5FGC1 } \\
\hline \multicolumn{5}{|l|}{5 Consultants $(\mathrm{CO})$} \\
\hline \multicolumn{5}{|l|}{$\begin{array}{l}\text { Consultant number one. Focus } \\
\text { groups. Cycle \# } 1 \text { (CO1FGC1) }\end{array}$} \\
\hline \multicolumn{5}{|l|}{$\mathrm{CO} 2 \mathrm{FGC1}$} \\
\hline \multicolumn{5}{|l|}{ CO3FGC1 } \\
\hline \multicolumn{5}{|l|}{ CO4FGC1 } \\
\hline CO5FGC1 & & & & \\
\hline
\end{tabular}


Table 1.b. The first cycle: Comparing and Organizing the Data

\begin{tabular}{|c|c|c|c|}
\hline \multirow{3}{*}{ Research Participants } & \multicolumn{3}{|c|}{ Second Discussion Point } \\
\hline & \multicolumn{3}{|c|}{$\begin{array}{c}\text { Discussing the role of financial aid in enhancing } \\
\text { degree completion }\end{array}$} \\
\hline & $\begin{array}{l}\text { Ambiguous } \\
\text { Explanation }\end{array}$ & $\begin{array}{l}\text { Unambiguous } \\
\text { Explanation }\end{array}$ & $\begin{array}{l}\text { Researcher's } \\
\text { Field Notes }\end{array}$ \\
\hline \multicolumn{4}{|l|}{5 Administrators (A) } \\
\hline \multicolumn{4}{|l|}{$\begin{array}{l}\text { Administrator number one. Focus } \\
\text { groups. Cycle \# } 1 \text { (A1FGC1) }\end{array}$} \\
\hline \multicolumn{4}{|l|}{$\mathrm{A} 2 \mathrm{FGC1}$} \\
\hline \multicolumn{4}{|l|}{ A3FGC1 } \\
\hline \multicolumn{4}{|l|}{ A4FGC1 } \\
\hline \multicolumn{4}{|l|}{ A5FGC1 } \\
\hline \multicolumn{4}{|l|}{$\begin{array}{l}20 \text { Female visible minority students } \\
\text { (F), focus groups participants (FG) }\end{array}$} \\
\hline \multicolumn{4}{|l|}{$\begin{array}{c}\text { Female visible minority student } \\
\text { number one, focus group, Cycle one } \\
\text { (F1FGC1) }\end{array}$} \\
\hline \multicolumn{4}{|l|}{ F2FGC1 } \\
\hline \multicolumn{4}{|l|}{ F3FGC1 } \\
\hline \multicolumn{4}{|l|}{$\ldots$} \\
\hline \multicolumn{4}{|l|}{ F20FGC1 } \\
\hline \multicolumn{4}{|l|}{5 Donors (D) } \\
\hline \multicolumn{4}{|l|}{$\begin{array}{c}\text { Donor number one. Focus groups. } \\
\text { Cycle \# } 1 \text { (D1FGC1) }\end{array}$} \\
\hline \multicolumn{4}{|l|}{ D2FGC1 } \\
\hline \multicolumn{4}{|l|}{ D3FGC1 } \\
\hline \multicolumn{4}{|l|}{ D4FGC1 } \\
\hline \multicolumn{4}{|l|}{ D5FGC1 } \\
\hline \multicolumn{4}{|l|}{5 Consultants (CO) } \\
\hline \multicolumn{4}{|l|}{$\begin{array}{l}\text { Consultant number one. Focus } \\
\text { groups. Cycle \# } 1 \text { (CO1FGC1) }\end{array}$} \\
\hline \multicolumn{4}{|l|}{$\mathrm{CO} 2 \mathrm{FGC1}$} \\
\hline \multicolumn{4}{|l|}{$\mathrm{CO} 3 \mathrm{FGC1}$} \\
\hline \multicolumn{4}{|l|}{ CO4FGC1 } \\
\hline CO5FGC1 & & & \\
\hline
\end{tabular}


Table 1.c. The first cycle: Comparing and Organizing the Data

\begin{tabular}{|c|c|c|c|}
\hline \multirow[t]{3}{*}{ The First Cycle (C1) } & \multicolumn{3}{|c|}{ Third Discussion Point } \\
\hline & \multicolumn{3}{|c|}{$\begin{array}{l}\text { Discussing the role of financial aid in enhancing } \\
\text { degree completion }\end{array}$} \\
\hline & Attainable plan & $\begin{array}{l}\text { Not attainable } \\
\text { plan }\end{array}$ & $\begin{array}{l}\text { Researcher's } \\
\text { Field Notes }\end{array}$ \\
\hline \multicolumn{4}{|l|}{5 Administrators (A) } \\
\hline \multicolumn{4}{|l|}{$\begin{array}{l}\text { Administrator number one. Focus } \\
\text { groups. Cycle \# } 1 \text { (A1FGC1) }\end{array}$} \\
\hline \multicolumn{4}{|l|}{ A2FGC1 } \\
\hline \multicolumn{4}{|l|}{ A3FGC1 } \\
\hline \multicolumn{4}{|l|}{ A4FGC1 } \\
\hline \multicolumn{4}{|l|}{ A5FGC1 } \\
\hline \multicolumn{4}{|l|}{$\begin{array}{l}20 \text { Female visible minority students } \\
\text { (F), focus groups participants(FG) }\end{array}$} \\
\hline \multicolumn{4}{|l|}{$\begin{array}{c}\text { Female visible minority student } \\
\text { number one, focus group, Cycle one } \\
\text { (F1FGC1) }\end{array}$} \\
\hline \multicolumn{4}{|l|}{ F2FGC1 } \\
\hline \multicolumn{4}{|l|}{ F3FGC1 } \\
\hline \multicolumn{4}{|l|}{$\ldots$} \\
\hline \multicolumn{4}{|l|}{ F20FGC1 } \\
\hline \multicolumn{4}{|l|}{5 Donors (D) } \\
\hline \multicolumn{4}{|l|}{$\begin{array}{c}\text { Donor number one. Focus groups. } \\
\text { Cycle \# } 1 \text { (D1FGC1) }\end{array}$} \\
\hline \multicolumn{4}{|l|}{ D2FGC1 } \\
\hline \multicolumn{4}{|l|}{ D3FGC1 } \\
\hline \multicolumn{4}{|l|}{ D4FGC1 } \\
\hline \multicolumn{4}{|l|}{ D5FGC1 } \\
\hline \multicolumn{4}{|l|}{5 Consultants $(\mathrm{CO})$} \\
\hline \multicolumn{4}{|l|}{$\begin{array}{l}\text { Consultant number one. Focus } \\
\text { groups. Cycle \# } 1 \text { (CO1FGC1) }\end{array}$} \\
\hline \multicolumn{4}{|l|}{$\mathrm{CO} 2 \mathrm{FGC1}$} \\
\hline \multicolumn{4}{|l|}{ CO3FGC1 } \\
\hline \multicolumn{4}{|l|}{ CO4FGC1 } \\
\hline \multicolumn{4}{|l|}{$\mathrm{CO} 5 \mathrm{FGC1}$} \\
\hline
\end{tabular}

